\title{
Strategy for Human Capital Management of MSMEs: A Conceptual Study
}

\author{
Sarita Mishra* \\ Srusti Academy of Management, Bhubaneswar, India \\ *Corresponding author: sarita@srustiacademy.org
}

Received August 25, 2014; Revised August 28, 2014; Accepted October 25, 2014

\begin{abstract}
The ever increasing number of employees in an organization, growth in business competitions and changing economic scenario compels the corporate to re-think about human management strategy. High attrition rate, absenteeism and migration of workforce compel the employer to rethink about the employee management. Most organizations actively look to reward hard-working employees by having an effective pay for performance. However two-third organizations have a pay-for -performance policy. Can it be possible to ensure this policy in MSMEs and other mediocre industries. Pay -for-performance, value analysis of individual employees, performance appraisal can only be possible by strategic implementation with the productivity of MSMEs. This article focuses on the concept of Human capital management, Research gap and a strategic model is suggested to face the challenges.
\end{abstract}

Keywords: human capital management, strategic model, pay-for-performance

Cite This Article: Sarita Mishra, "Strategy for Human Capital Management of MSMEs: A Conceptual Study.” Journal of Business and Management Sciences, vol. 2, no. 3A (2014): 46-48. doi: 10.12691/jbms-2-3A-7.

\section{Introduction}

The journey of employee management is becoming the most challenging issue for entrepreneurs. High attrition rate, absenteeism and migration of workforce compels the employer to rethink about the employee management. The business performance and market existence can only be possible by the experienced work force. These experienced workforce are the human capital for the organizations. The employees are treated more like investors of their own capital but can rent it from their employees. In fact, human capital is highly precarious and is in constant danger of being lost when an employee quits the organization Human capital is the stock of competencies, knowledge, social and personality attributes, creativity embodied in the ability to perform labor so as to produce economic value. Human capital management enables companies to value their employees, to measure and communicate this value and systematically manage it.

The entrepreneurs must address these aspects to understand the value of an employee in an organization. The value of employee needs to be recognized and steps must be taken to improve these capacities and skills. Human capital is similar to physical means of production, i.e. Factories and machines and one can invest in human capital through education, training and medical treatment and one's output depend partly on the rate of return on the human capital one owns. Thus, human capital is a means of production into which additional investment yields additional output. (Adam Smith) Human capital management recognizes that people are investors of their personal human capital and this provides the main source of value for an organization. The skills, potential, knowledge base, attitude towards work, experience must be identified of each employee and utilized for the utmost output. In fact, the employee's ability and competency must be mapped timely or through a schedule. This has been realized by the big corporations like Orissa Mining corporations. Unfortunately this has not been realized by the micro small medium enterprises. India is the second largest home market for small and medium sized enterprises. This sector alone offers employment to 6 cores people approximately and produces more than 8000 products. In reality these sector face the challenges for human resources like attrition rate and retention of the right manpower. The issues related to employee management, procurement, training, retaining and enhancing the value amongst workers need to be addressed by the micro small medium enterprises and the entrepreneurs of these sector need give focus on these areas.

\section{MSMEs: The Research Gap}

Micro small medium enterprises have been neglected by the researchers as well as academicians for a longer period of time. In fact there is no such clear cut picture available for MSMEs of India. The statistics on investment provides a fathom on the reality existence of micro small medium enterprises. The micro, small and medium enterprises in India has grown at an annual rate of growth about $5 \%$ in terms of investment, the sector has grown by $10 \%$ and the employment in the sector has also increased. (Aisha de Sequeira, MD, Morgan Stanley, Head Investment banking in India). Indeed, these statistics can be used as an yard stick for understanding the status of 
MSMEs in India. However, it is interesting to note that there is no database of the workforce engaged in different sectors of MSMEs, the requirements of skill level, training and mentoring and evaluation of those employees. In fact, Small entrepreneurial organizations need low investment and they offer employment to the local talents. However due to this reason they face resource limitations of human and non-human. Flexibility and closeness to the customers are the major advantages, due to informal settings these organizations can strike the local market demand and suffer from lack of economies of scope due to limited exposure. (Krik and Noonan, 1982, Nooteboom, 2002) These organizations are the outcomes of initiatives of entrepreneurial talents. A small medium enterprise is itself a challenging task, as every country have their own definition for Small Medium Enterprise. In a country like India as per the micro, small and medium enterprises development Act 2006, enterprises are broadly classified into micro units, small units, medium units and large units depending on the investment on plant and machinery. 4 In reality the grey area of MSMEs are given less emphasis on research and development of the organization as well as capitalizing the value of employee at MSME.

The research gap of MSMEs is analyses from the selected research works in the field of MSMEs.

"Growth of small organizations is influenced by three major factors- the background/resource of the entrepreneur, the nature of the firm and strategic decisions taken by the own/ manager." (Storey 1994) “The core competence gives a company competitive capability and remains central to it's strategy planning thus helps the company to establish in the market.”(Hamel \& Prahalad 2002)“The entrepreneur needs to develop both strategic and tactical skills and abilities. (Kuratko et.el 2001)The major problems in evaluation of growth of small organizations is analyzed by O'Farrel and Hitchins. There is a major inconsistency in defining the small firms.-There are also inconsistencies in the dimensions of growth; employment, profit, value added, turnover, total asset and market share (O’Farrel and Hitchins 2002) High performing small manufacturing firms emphasize on new product development, product improvement, product quality and customer service and the related performance indicators are adoption of new performance methods, employee productivity and efficiency and employee welfare. (Kotey and Meredith 1997).

These research extracts are the prelude to understand that there is no such research is taken up in human capital management of MSMEs. In fact, the experienced and capable workforce is the real contributor to the growth of micro small medium enterprises. The identification of that workforce and managing the work force is the challenge for today. This can only be addressed by the appropriate research and implementation of a strategy for the workforce.

\section{Strategy for HCM of MSMEs: A Model}

\subsection{SWOT Analysis}

Strength, weakness, opportunities and threats analysis is one of the primary step for all business units. The business units basically implement it from the organizational point of view to understand their strength factors (Machinery, infrastructure, product, service quality), weakness (Lagging factors like implementation of new technology, skilled manpower and market presence), Opportunities (Penetration to new segment areas and new product development) and treats (emerging competitors).In fact like big corporate giants like TCS, Infosys, Wipro these small units never thought of quality of work life at their units. The quality of work life at small business units only possible through the evaluation of the strength of manpower. The total man hour contributed by the employees needs to be addressed by the employer. The employers are required to prepare the inventory of the skilled manpower, commitment level of the employee and experience on the particular work of the employee. This will provide a basic step to understand the value of the employee and need of the employee in a particular business unit. And the report by the working group of MSME reveals that lack of skilled manpower and information as well as lack of reach to modern technology are key issues affecting the growth of MSME sector. India is one of the developing country having demographic dividend compared to rest of the world due to its huge population in productive age group. Most of the other developed as well as developing countries face the threat of an aging population. If this comparative advantage can be augmented with adequate skill development, India can become the global supplier of the quality manpower. Ministry of MSME has decided to accord top priority to skill development. The ministry conducts a large number of short term as well as long term courses to train unemployed youth for self- employment, to provide necessary skill to the youth to make them eligible for wage employment and also to upgrade the skill level of existing workers and entrepreneurs of MSME sector Indeed these steps are not creating the talent pool for the MSMEs. Upgrading skill, nurturing the skill, utilization of skill at a business unit and retaining skill for the said unit is need to be addressed by the entrepreneurs. This can only possible if the employer will create the record of the workers, skill level, and experience on a work and commitment level of worker to the unit. These steps will help to accord the value of the worker in the said unit and capitalizing the value for better productivity.

\subsection{Risk Identification}

Risk identification by the employers in hiring talented workforce. Small medium enterprises must understand the difference between the traditional and the conventional approach of talent attraction. The focus must be given on recruiting individuals with appropriate skills using suitable evaluation procedures that verify the candidates expertise. The entrepreneurs should involve themselves while hiring the people at senior positions for an unit. It requires the expertise and experience to handle the unit as per the market situation. To control the talent flight, to retain the talent at the senior and to procure the talent for the senior level is one of the challenging job for the entrepreneur. This has been realized by Mr Sanjay Modi, $\mathrm{MD}$, Monster. India, he said" I do not worry about the time spent on hiring process as our focus on productivity enhancement will only happen if I have the right talent in 
place.” Hence, the human capital risk occurs when the organization operates below attainable operational excellence levels (Lower than the achievable target). Absence of activities due to sick leave, absenteeism and industrial conflicts are the leading causes for the wastage of human capital in any business unit. In fact, the activities which includes rework, consecutive meetings which involves all employees and manual data transfer are also the leading causes of wastage of human capital. Hence, identification of risk areas in hiring, procuring and utilizing the talent requires strategy for the proper utilization of human capital.

\section{KSW Approach and Competency Mapping}

Knowledge, skill and willingness can be utilized in an integrated manner. The entrepreneurs of sick units as well as the prospering units must identify the employees having these three aspects. The domain knowledge, specific skills to handle the work and willingness of the employee can provide a better platform to utilize the human capital. On the other hand competence mapping of the workers must be taken up by the organization from time to time which will help to understand the lagging areas of the worker. The entrepreneurs can formulate the strategy by using KSW approach for product innovation, improving service quality and improving work culture.

\section{Competitive Advantage with Merger and Acquisition}

The sick units must think of either merging with the other unit or think up acquisition of another unit The merger and acquisition process must be based on the strategy of competitive advantage. If the units are not having any market presence then it will be a failure for merger and acquisition process. The statistics there are 527 handicrafts and cottage industries, 1233 small scale industries and 1841 large and medium industries in Orissa. If this is the status then the presence of this sector must be given priority in all over the country. In reality most of the sectors are facing financial problems and enlisted in sick category. A conscious effort has been taken up by Confederation of Indian Industries through cluster approach to make the SMEs more competitive. In reality competing with the other units will not help to utilize the benefit of competitive advantage. The feasibility analysis and reporting services for MSMEs to prepare proposal for funding or joint ventures supported by CII. This software only supplement the analysis of the project whether to go for a new investments, rehabilitations, expansions, joint venture or privatization of projects. This is limited to the feasibility aspect and not providing a total approach for the market presence. The units must be created on the basis of the market requirement and customers need which will give the benefit of competitive advantage on existing market.

\section{Challenges}

The following challenges are emerged from the analysis on human capital management of MSMEs.

- Standardizing the curriculum for the training programme to be implemented uniformly all over India.

- Dynamics of job market-The job market place has undergone paradigmatic shift for the last few years. The weak candidate engagement in an enterprise leads to wastage of resources. Recruiting the right candidate from the job market where supply is more, is becoming a real challenge for the entrepreneur.

- No clarity on role and responsibility-Role clarity is one of the major ingredients for successful work force. Most of the candidates are accepting the roles without asking for responsibility.

- Strategic formulation-The dynamics of market scenario is acting as an obstacle for formulation any strategic decision for MSMEs.

- Work Life Balance-Implementation of work life balance for the entrepreneurs as well as the work force is a distant dream.

\section{References}

[1] Ingam, J. (2007). Strategic Human Capital Management. Butterwoth Heinemann.

[2] www.Wikipedia

[3] www.maritnwolters.com

[4] www.economywatch.com

[5] Majumdar, S. Growth Strategy in Small Entrepreneurial Business organizations: A Conceptual Model. T. A. Pai Management institute, Manipal.

[6] The Orissa Gazette. (2009). Cuttack, Monday, March-9, 351.

[7] www.Moneycontrol.com.

[8] Report on MSME, Dept of Industries, Govt. of Odisha. 